\title{
MAKE ROOM FOR WLDLIFE. A RESOURCE FOR LOCAL PLANNERS AND COMMUNITIES IN THE ADIRONDACKS
}

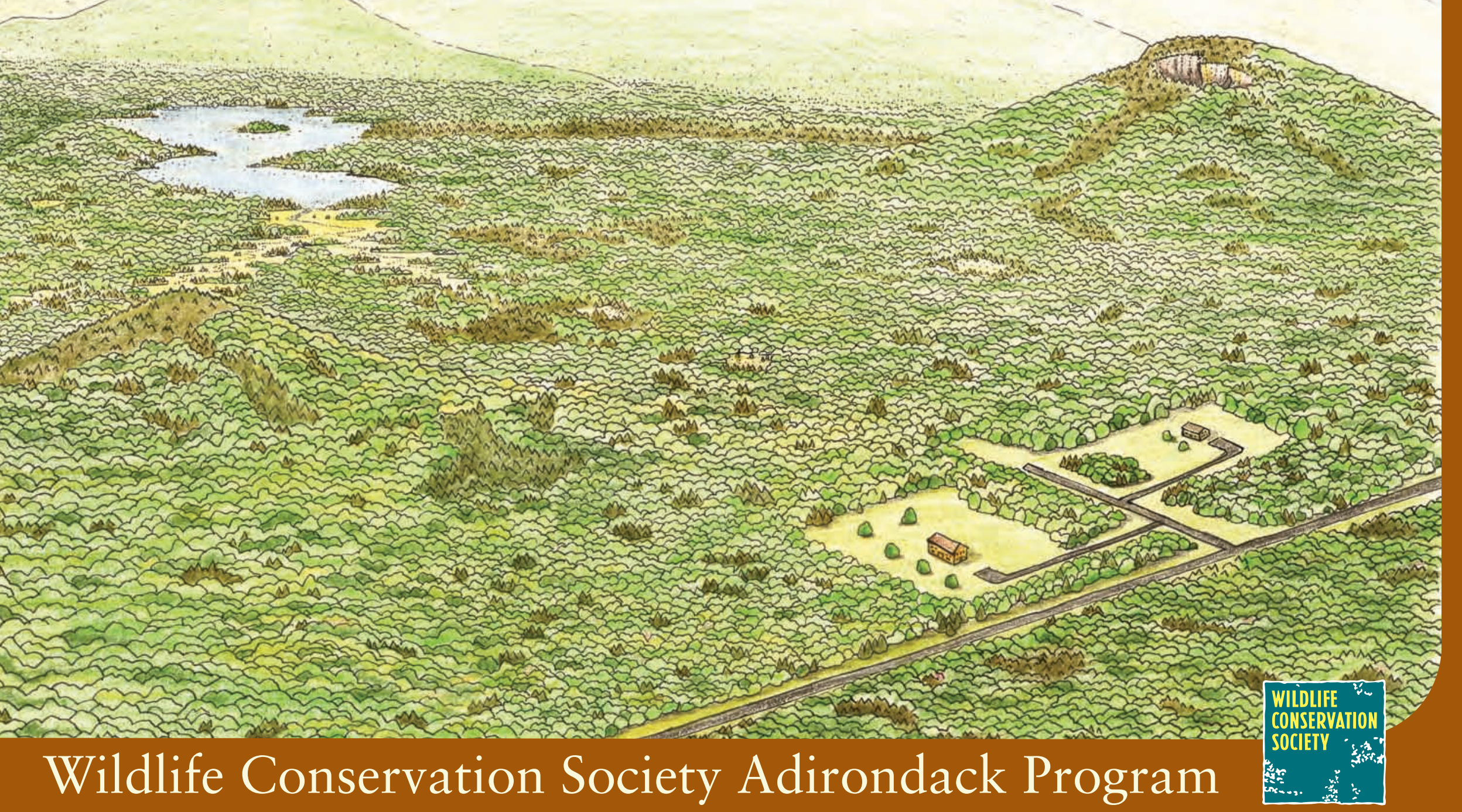




\section{WHAT NATURAL FEATURES ARE IN YOUR TOWN?}

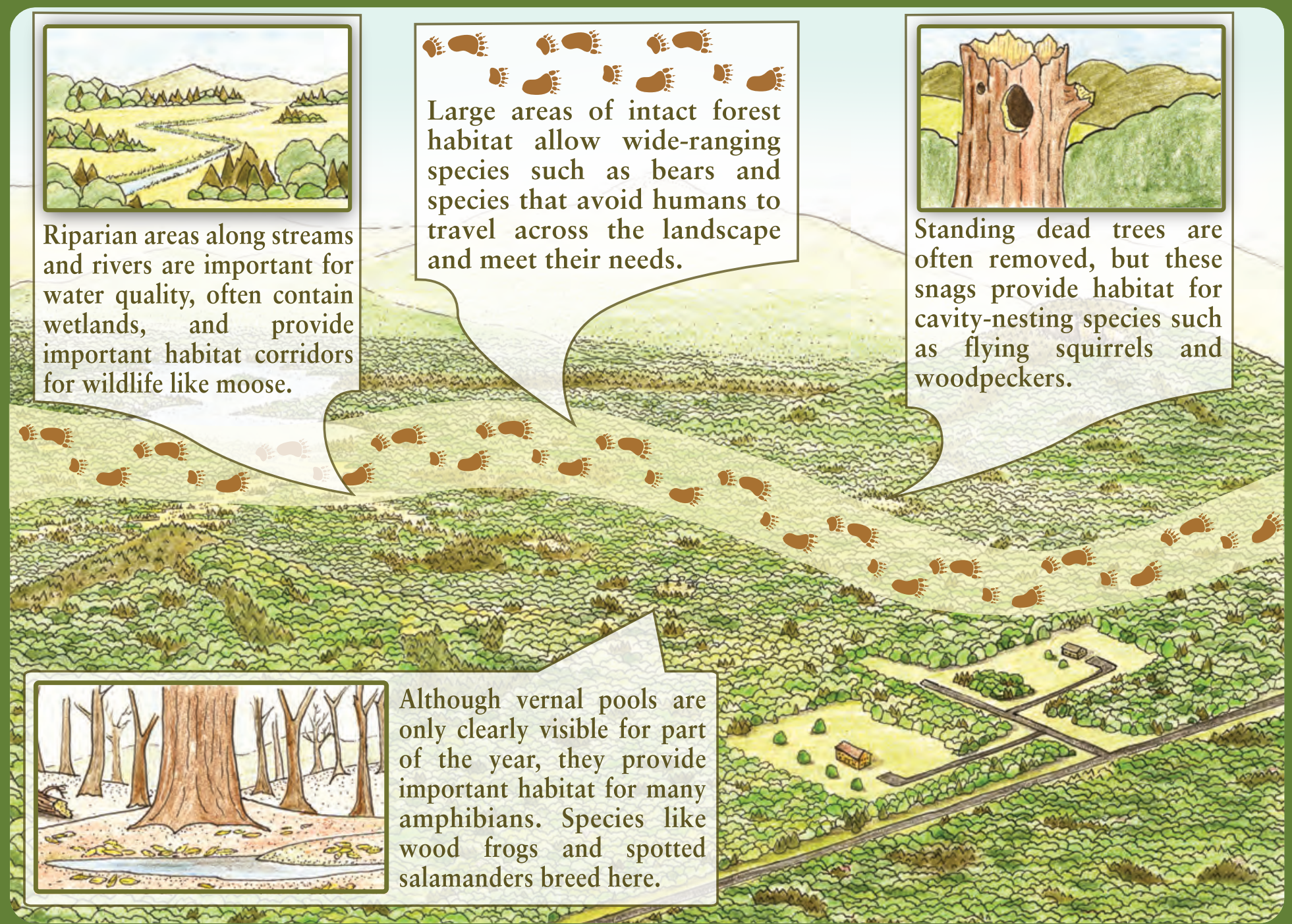

Riparian corridors, vernal pools, large blocks of intact forest, and snags are just a few of the natural features that provide important wildlife habitat in the Adirondack landscape. Features such as these are often overlooked, however. Recognizing and identifying these features is the first step to protecting wildlife, even while pursuing development opportunities. 


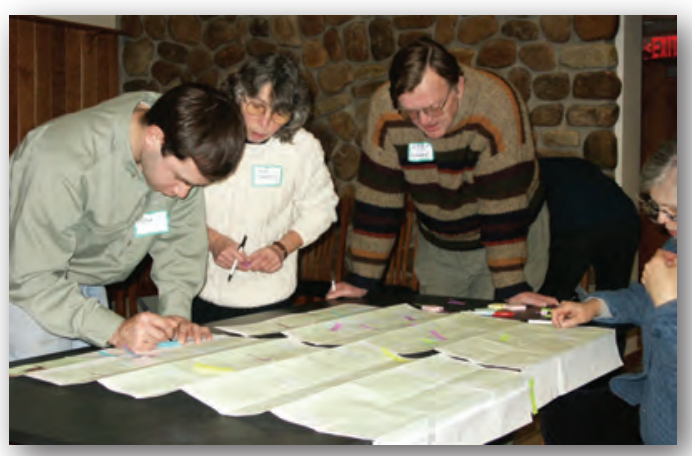

WILDLIFE AND RESIDENTIAL DEVELOPMENT

This pamphlet will help local planners and communities in the Adirondacks consider wildlife in developing land-use plans and reviewing proposals. Although the state lands of the Adirondack Park protect large expanses of habitat, many animals require or prefer habitats found on the privately owned lands of the park. To maintain the incredible wildlife found here, Adirondack residents must be thoughtful-and smart-about how to develop private lands.

Town boards, planning boards, and local zoning boards of appeal play an important role in protecting wildlife when reviewing proposals under their jurisdiction and exercising planning as authorized by state law.

Habitat loss and fragmentation are two of the most significant threats facing wildlife species in the Adirondacks and elsewhere. Communities can take advantage of many planning principles and tools in order to plan for growth while minimizing adverse effects, protecting wildlife, and enhancing community values. The guidelines in this brochure offer opportunities to work towards this goal.

\section{IF YOU ARE THINKING ABOUT THE FUTURE OF YOUR COMMUNITY}

Whether you are working on a new comprehensive plan, land-use code, subdivision regulations, or other local planning tools, you have an opportunity to shape your community in the long term. Under state law, towns and villages in New York have reasonably broad jurisdiction to adopt local planning. Use this power for the long-term benefit of both people and wildlife in your community!

- Plan ahead, ask for help, and set goals for conservation-Make wildlife and biodiversity conservation a primary goal of your planning effort from the outset. Obtain help from local scientists and natural resource managers: New York Natural Heritage Program, the New York Department of State, the Adirondack Park Agency, Audubon New York, the Wildlife Conservation Society, and others.

- Identify what you have and what is vulnerable, sensitive, or ecologically important-Good information leads to a strong plan. Gather information about the natural features of your community as part of the planning process.

Consult the groups listed above for assistance. Give developers, landowners, and planners within your community access to information to ensure its use in planning future development.

- Think regionally-Does your town have forests, rivers, streams, or wetlands that cross municipal boundaries? If you are developing a comprehensive plan, consider making it an intermunicipal plan. If this is not possible, show that your community exists in a wider ecological context.
- Include goals that capture your community's conservation values-If you are developing a comprehensive plan, your work will set the precedent for land-use planning in your community for years to come. Explicitly state the attributes of your natural environment that you wish to protect and preserve.

- Encourage efficient use of land-With limited private land available for development in the Adirondack Park, it makes sense to encourage dense, clustered development. Clustering development, rather than spreading it out over the landscape, protects open space, protects wildlife habitat, and minimizes need for infrastructure. Adopt local guidelines to encourage clustering or adopt conservation design principles such as conservation overlays to convey the importance of using land efficiently to everyone in the community.

- Be aware of the variety of tools available for protecting open space-There are many sources of information on regulatory tools such as conservation overlay zones, transferable development rights, conservation subdivisions, easements, and cluster or open space zoning for protecting wildlife and habitat in the context of residential development. See the "Getting Started" section of this brochure. 


\section{IF YOU ARE REVIEWING A SUBDIVISION PROPOSAL}

Subdivisions create an irreversible effect of dividing the landscape and causing habitat loss. However, there are many ways that you can work with developers to minimize the negative impacts of subdivisions.

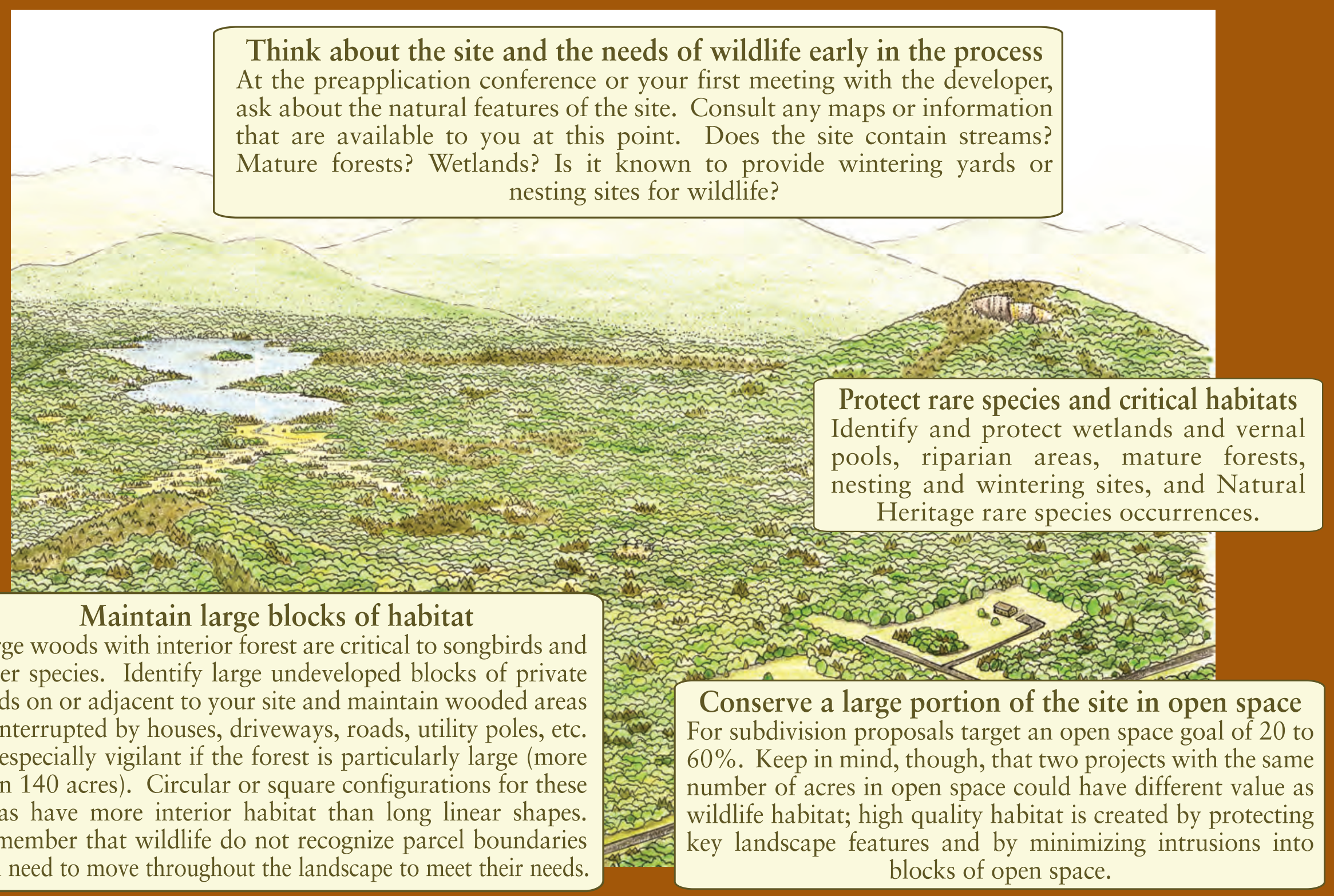




\section{INSTEAD OF THIS}

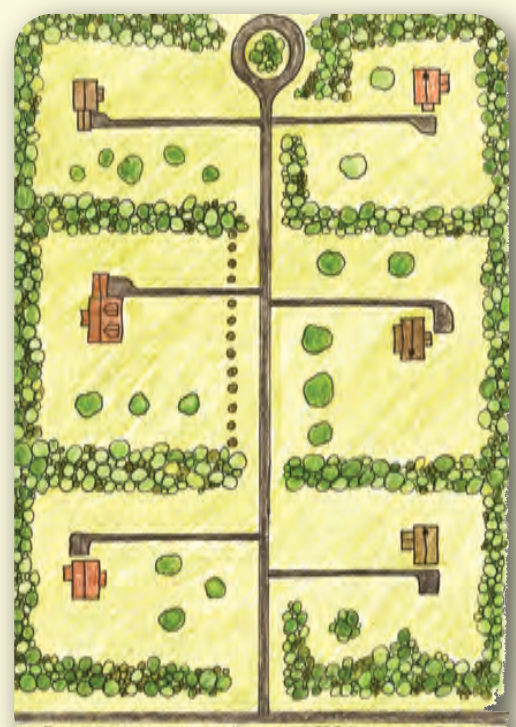

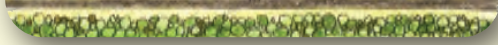

Clustering homes helps maintain most of the site in a natural condition, preserves large contiguous habitat blocks, reduces new road construction, and limits the area of human disturbance. Cluster homes whenever possible, and minimize the footprint of homes by limiting the allowable size of lawns. Clustering and minimizing new road construction will reduce the carbon emissions of a project-both in the short term (from clearing the forest for construction) and in the long term (when land-use designs result in ongoing transportation patterns).

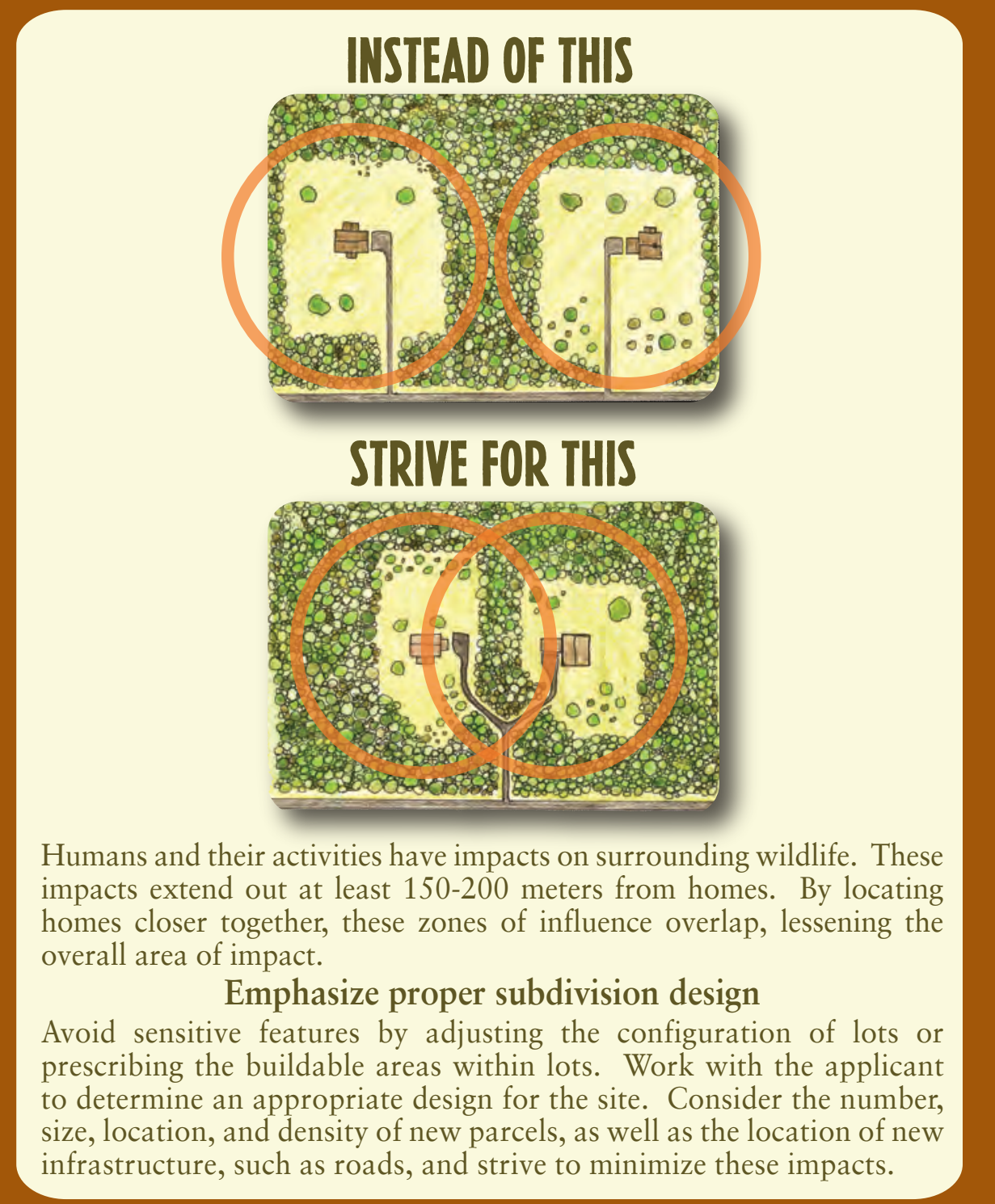




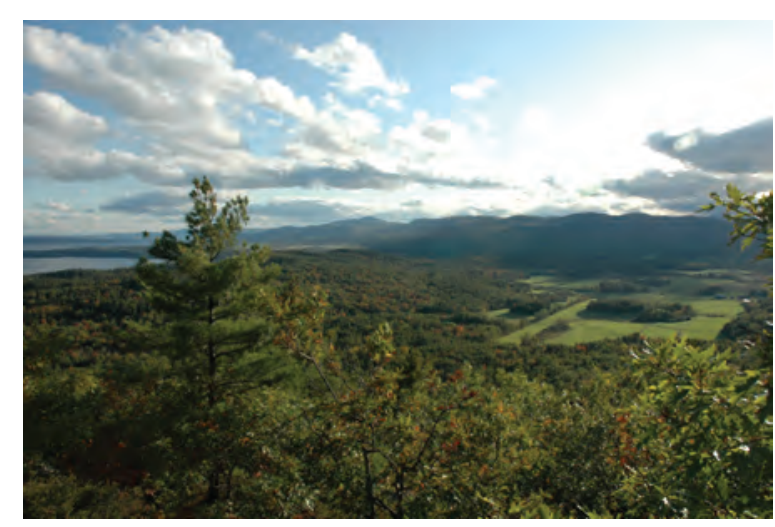

SEEKING SENSE IN SEQR

Whether you are considering adopting a comprehensive plan, reviewing a site plan or subdivision proposal, or considering a variance, you are probably obligated to comply with SEQR, the State Environmental Quality Review Act. Impacts to open space, water quality, and plants and animals are all considerations that agencies must evaluate in determining the significance of an action under SEQR. Type I and Unlisted actions require an Environmental Assessment Form (either short or full) to be completed. The lead agency (often a local town or planning board) must make a discretionary judgment about the magnitude and importance of these impacts. The Environmental Assessment Form provides a framework for specific factors to consider, including impacts to habitat and wildlife. Although many actions with some potential impact on wildlife may ultimately not require a detailed SEQR review, local agencies should take advantage of the opportunity to consider all of the potential impacts of an action on the community.

\section{IF YOU ARE REVIEWING A SITE PLAN}

\section{Understand the site and its context} Gather available information and ask the applicant questions early in the process about the natural features and wildlife habitats of the site, and keep the big picture, such as nearby features, in mind.

\section{Understand the proposal and identify potential impacts}

Will the proposed activity impact rare species or critical habitats? Will it infringe upon large forest blocks, or create new roads and edges? Edges between forests and open space created by lawns, roads, and other features can negatively influence some kinds of wildlife. Identify these ecological impacts, and identify ways you can work with the applicant to minimize or mitigate them.

\section{Maintain appropriate buffers}

Development should be separated from features like rivers, lakes, streams and wetlands to protect water quality and maintain wildlife's ability to use and move along these features. Avoid locating development within 100 meters of these features.

\section{Minimize the spread of non-native, invasive species}

Encourage or mandate using native species in landscaping plans, and minimize roads and edges, which provide pathways for invasive species.

\section{Consider the type and timing of construction activities}

Avoid undertaking construction activities during critical amphibian movement and migration times or bird nesting seasons (primarily spring and early summer). Time construction in late summer, fall, (and winter, where possible) to minimize impacts to many wildlife species that breed in spring in the Adirondacks.

\section{GETTING STARTED}

Integrating wildlife needs into local planning efforts may seem like a daunting task but many resources exist to assist you in this rewarding effort. If you have questions about this document, would like links to or lists of additional resources, or would like to work with us to determine ways that you can protect wildlife habitat through local planning in your community, please visit our website www.wcs.org/adirondacks or contact us at accp@wcs.org

\section{ABOUT US}

The Wildlife Conservation Society saves wildlife and wild lands through careful science, global conservation, education, and the management of the world's largest system of urban wildlife parks. These activities change attitudes toward nature and help people imagine wildlife and humans living in sustainable interaction on both a local and global scale. WCS is committed to this work because we believe that it is essential to the integrity of life on Earth.

A field program of the Wildlife Conservation Society, the WCS Adirondack Program works to promote healthy communities and wildlife conservation in the Adirondacks through an information-based, cooperative approach to research, community involvement, and outreach.

We gratefully acknowledge the support of the Doris Duke Charitable Foundation through the Wildlife Action Opportunities Fund for the production and distribution of this brochure.

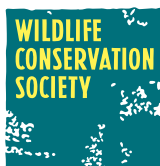

ADIRONDACK PROGRAM 


\section{WHICH WILDLIFE WILL THANK YOU?}

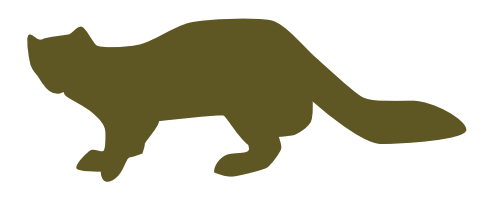

pine marten

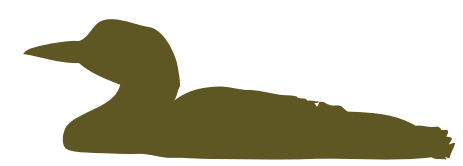

common loon
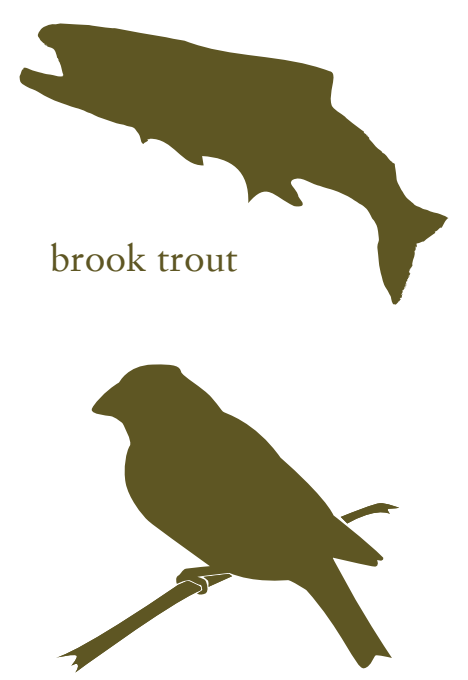

evening grosbeak

\section{Wide-ranging animals}

Black bear, bobcat, marten, fisher, and moose are examples of species that need lots of space and will appreciate planning that protects large, well-connected forest blocks. Wildlife species do not heed political or land-ownership boundaries. Thinking on broader scales and considering daily and yearly movement needs helps maintain healthy wildlife populations.

\section{Amphibians and reptiles}

Amphibians and reptiles are particularly susceptible to the impacts of roads and other fragmenting features because they use a variety of habitat types during their life cycle.

Some, like turtles, do not even begin to reproduce until they are quite old ( $>20$

years). Minimizing roads and using techniques to make roads as wildlife-friendly and permeable as possible will greatly enhance survivorship of reptiles and amphibians.

\section{Interior forest dwellers}

Edges between forests and openings like roads or lawns pose many dangers, and some species will not use forests that are fragmented by roads and houses.

Maintaining large forest blocks with plenty of interior habitat will ensure suitable areas for species like scarlet tanager, ovenbird, and American marten.

\section{Small mammals}

Small mammals are a critically important food source for a variety of species like marten, fisher, fox, and coyote. Maintaining snags and downed woody debris associated with old-forest conditions will help maintain microhabitats that support diverse, abundant small mammal faunas. Similarly, minimizing roads and the size of lawns will help curb indiscriminate loss of these species.

\section{Adirondack icons}

Moose and bears are wide ranging and commonly suffer from vehicle collisions as they make their way across our Adirondack landscape. Clustering development and minimizing road construction helps reduce these losses. Loons, herons and other aquatic species will benefit from buffering water features like rivers, lakes, and wetlands from shoreline development.
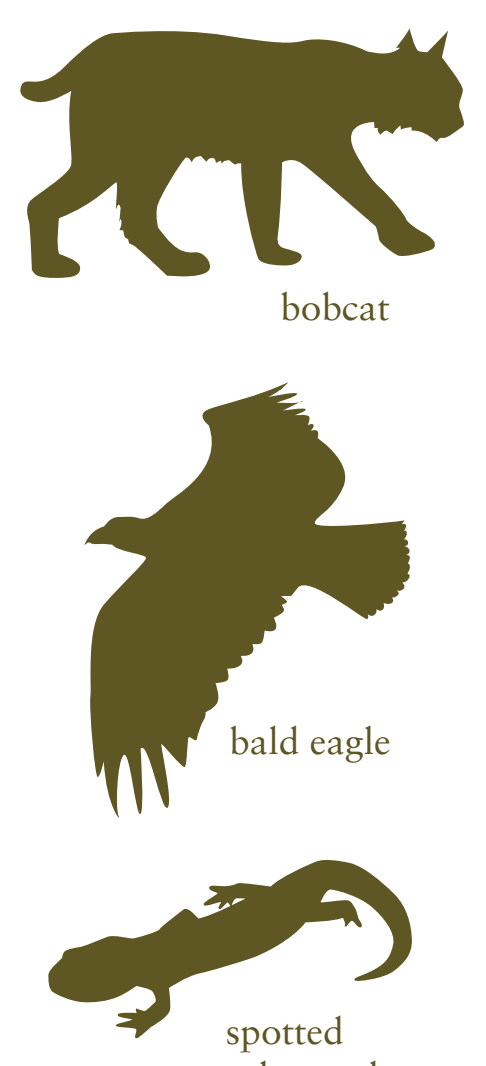

salamander

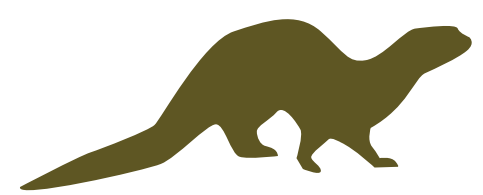

otter

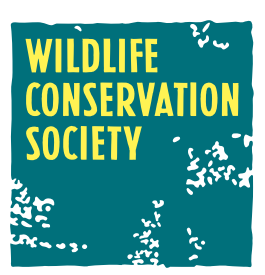

ADIRONDACK PROGRAM

7 Brandy Brook Avenue Suite 204

Saranac Lake, New York 12983

518-891-8872 www.wcs.org/adirondacks accp@wcs.org

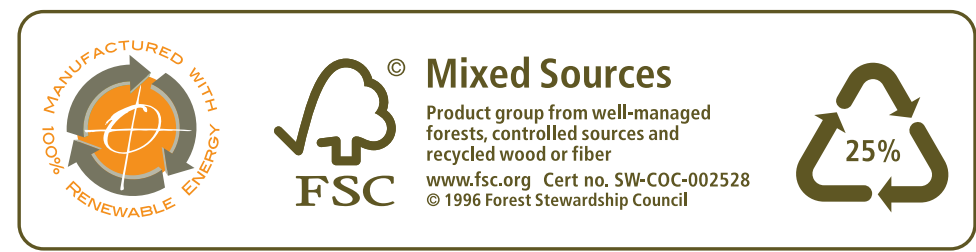

